\title{
Analysis of the Optical Properties of Screen-Printed and Aerosol-Printed and Plated Fingers of Silicon Solar Cells
}

\author{
R. Woehl, M. Hörteis, and S. W. Glunz \\ Department of Silicon Solar Cells-Development and Characterization, Fraunhofer Institute for Solar Energy Systems, \\ Heidenhofstr. 2, 79110 Freiburg, Germany \\ Correspondence should be addressed to R. Woehl, robert.woehl@ise.fraunhofer.de
}

Received 10 June 2008; Revised 31 July 2008; Accepted 14 August 2008

Recommended by Armin Aberle

One main efficiency loss in industrial solar cells is the shading of the cell caused by the metal front side contacts. With the aerosol-printing technique plus an additional light-induced plating (LIP) step, not only is the geometrical contact width narrowed compared to screen-printed contacts but also the shape of the finger changes. In this work, the effective shading of different finger types is analysed with two different measurement methods. The essential parameter for characterising the finger is the effective width which can be reduced drastically compared to the geometrical width due to total internal reflection at the glass-air layer and the reflection from the roundish edges of the contact fingers into the cell. This parameter was determined with different methods. It could be shown that for aerosol-printed fingers the effective (optical) width is only $38 \%$ of its geometrical width, while for standard screen-printed fingers it is $47 \%$. The measured values are compared to a theoretical model for an aerosol-printed and plated finger and are in good agreement.

Copyright () 2008 R. Woehl et al. This is an open access article distributed under the Creative Commons Attribution License, which permits unrestricted use, distribution, and reproduction in any medium, provided the original work is properly cited.

\section{Introduction}

Conventional silicon solar cells produced in the industry possess, in addition to busbars, many metal fingers on the front side of silicon solar cells. The fingers should conduct the current with as little resistance loss as possible which leads to a necessary minimum of cross-section of the finger. Since at the same time the metal fingers cause shading losses, the aim is to produce fine lines with a high aspect ratio (ratio of height to width).

One route Fraunhofer ISE follows is to use a two-step metallisation technique. In the first step, the seed layer is created which forms a good mechanical and electrical contact to the silicon surface. In this work the seed layer is printed with an aerosol printer from the company Optomec (Saint Paul, Minn, USA). The specially prepared ink is sprayed into an aerosol (for details see $[1,2]$ ) and is directed to the printing head. This head consists of 10 identical nozzles in a row. The so-called sheath gas flow focuses the aerosol and avoids that the aerosol gets in contact with the inner surface of the nozzle. The seed layer has a width of about $50 \mu \mathrm{m}$. After printing, the cell has to be fired at a temperature of $800^{\circ} \mathrm{C}$.
The second step is the light-induced plating (LIP). During this process, the fingers are thickened about $20 \mu \mathrm{m}$ with silver in order to receive good line conductivity. In the configuration, the whole solar cell is placed into a silver bath. The rear side must be contacted and the front side illuminated. Due to the photovoltaic effect, the potential on the front surface becomes negative so that the silver ions are deposited on the front contacts. With the LIP method, highefficiency solar cells of over $23 \%$ can be achieved [3] and industrial inline processing can be used [4].

With this technique about $70 \mu \mathrm{m}$ wide contacts on a monocrystalline, textured surface with an antireflection coating (ARC) were achieved (see Figure 1).

Compared to a standard screen-printed contact (see Figure 2), it clearly has the advantage of a smaller geometrical width $(72 \mu \mathrm{m}$ compared to $130 \mu \mathrm{m})$. Furthermore, the two contact fingers differ in their shape, which should influence their reflection properties. Especially for the aerosol-printed finger light could be reflected directly or via total internal reflection at the module glass-air interface onto the active area of the cell, thus reducing the effective shading of the finger. 


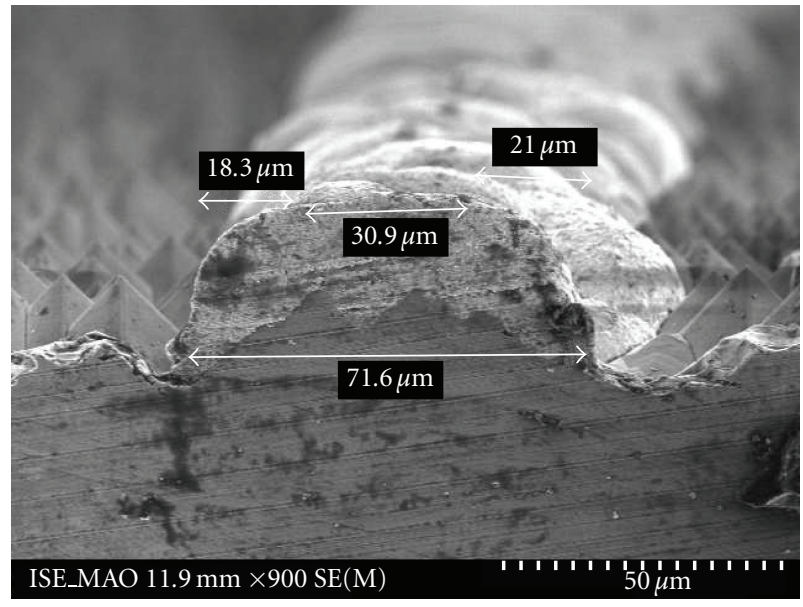

Figure 1: Cross-section of an aerosol-printed and plated finger exhibiting a geometrical width of $72 \mu \mathrm{m}$. The seed layer width was approximately $50 \mu \mathrm{m}$ and the plated silver about $20 \mu \mathrm{m}$.

Blakers [5, 6] and Stuckings and Blakers [7] have already analysed this effect for contact fingers with a seed layer width of 3.5-8 $\mu \mathrm{m}$ and postplated silver using measurement of the global short-circuit current and global reflection. They have observed a great reduction of the effective optical width of the contacts to about a third of the geometrical width.

The main motivation of this paper is to analyse if the contact fingers fabricated with the industrial feasible aerosol jet printing technology will also show such a dramatic reduction and to compare the optical performance of these fingers with the standard industrial screen-printed contacts. To achieve this goal, we have used the methods suggested by Stuckings and Blakers in addition to locally resolved measurements of the reflection.

\section{Theoretical Considerations}

For the calculation of shading losses of the solar cell, the determining factor for the fingers is not the geometrical width, but the effective (optical) width. It is the fraction of the geometrical (measured) width that actually shades the solar cell. The effective width can be significantly smaller than the geometrical width because light can be reflected from the finger to the cell and therefore contribute to the power generation.

Blakers $[5,6]$ has calculated the effective shading of a roughly half-circular encapsulated finger to be $36 \%$. The nearly optimum half-circled shape was achieved by a very narrow seed layer and a subsequent silver electroplating step. He compared this value with $j_{s c}$ measurements of cells covered with isopropanol and found excellent agreement. Stuckings and Blakers [7] also calculated the theoretical effective width of a half-circular encapsulated finger and found a similar value of $34 \%$. He compared this value to reflection measurements and determined experimental values between $30 \%$ and $35 \%$ which is in good agreement with the theoretical value. In this work, on the one hand, the finger structures are quite different from the previously

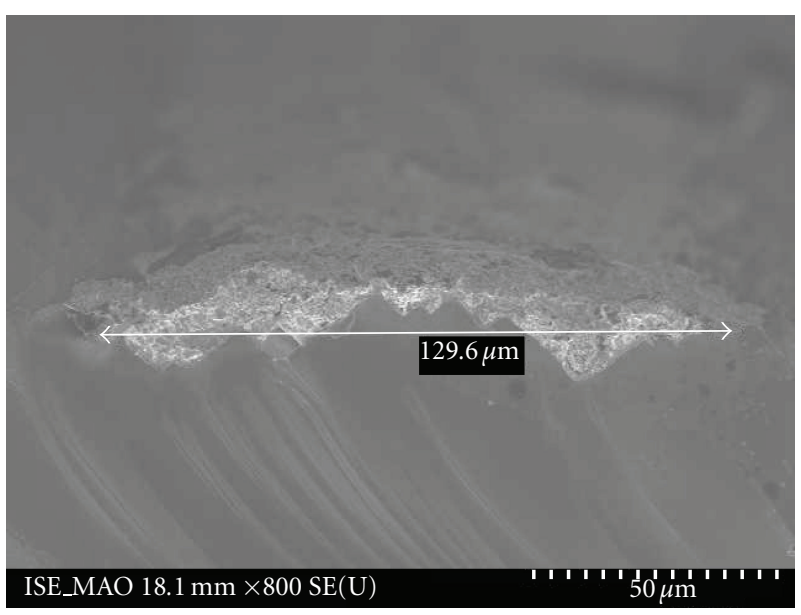

FIGURE 2: Cross-section of a screen-printed finger exhibiting a geometrical width of $130 \mu \mathrm{m}$.

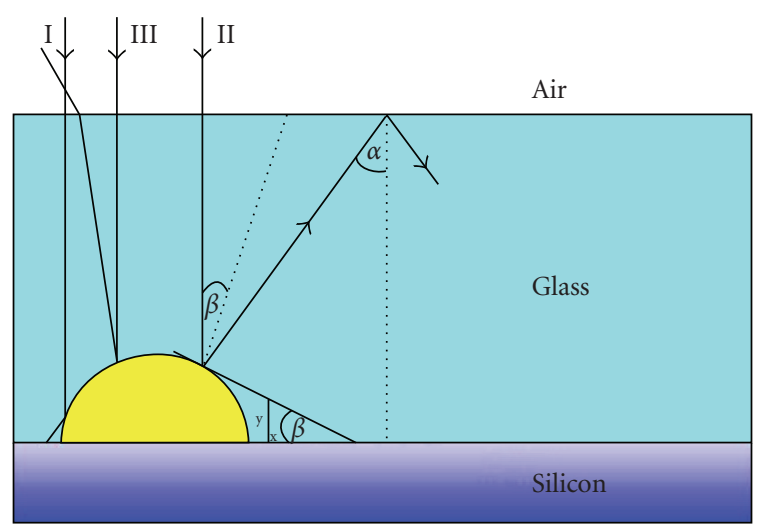

Figure 3: Three different cases for the reflection of the light from the finger. The pottant between the silicon and glass is not illustrated because it has about the same refractive index as the glass and therefore no influence on the optics.

investigated ones due to the wider seed layer and, on the other hand, the striking question is if the aerosol-printed fingers are beneficial compared to the screen-printed ones.

Assuming that the light hits the finger perpendicular to the encapsulated cell (see Figure 3), there are three different cases for the light to be reflected:

(I) direct reflection onto the silicon surface;

(II) total reflection can occur at the boundary layer glass air;

(III) the light can be reflected out of the module.

For cases I and II, the light can contribute to current generation and therefore reduces the effective width. In order to determine the lateral $x$-position for the simple case of a half-circular shaped finger, where total reflection occurs, the refractive index of the glass has to be measured. In the wavelength range of $600-1000 \mathrm{~nm}$, a value 
Air

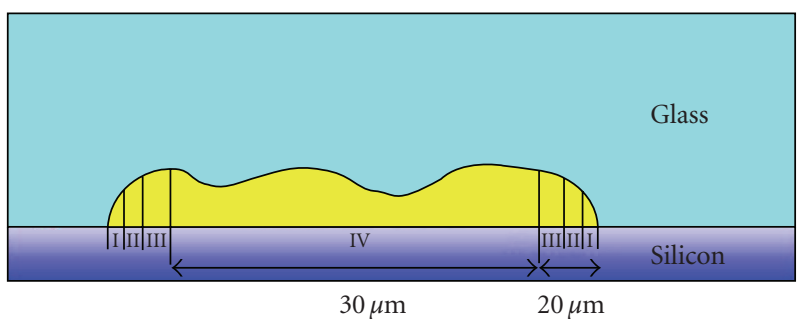

FIGURE 4: Sketch for the aerosol-printed and plated finger with the four areas that have different reflection properties.

of $n_{\text {glass }}=1.528 \pm 0.007$ was determined. With the refractive index for air $n_{\text {air }}=1$ and Snells law

$$
\alpha=\arcsin \left(\frac{n_{\text {air }}}{n_{\text {glass }}}\right),
$$

the critical angle for total reflection is $\alpha=40.9^{\circ}$. The (upper) angle $\beta$ is the half of the alternate angle of $\alpha, \beta=20.4^{\circ}$. This angle can be found as well between the silicon and the tangent of the half circle. The gradient of the tangent is $-\tan (\beta)=-0.37$ and can be set equal with the derivation of the equation of a half circle $\left(f(x)=\sqrt{1-x^{2}}\right)$

$$
f^{\prime}(x)=\frac{-x}{\sqrt{1-x^{2}}}=-0.37 \text {. }
$$

If the origin is set at the middle of the circle, it follows that the light hitting the finger at a position $-0.35>x>0.35$ (assuming a unit circle) total reflection occurs. The situation changes to case $I$ at a tangent smaller than -1 with an $x$ position of 0.71 . Thus the fraction of the area of a half-circled finger can be assigned: $\mathrm{I}=29.3 \%$, II $=35.8 \%$, and $\mathrm{III}=34.9 \%$.

For the aerosol-printed and plated finger, however, the cross-section looks slightly different. As can be seen in Figure 1, the flanks are indeed similar to a quarter circle, but the finger has a $30 \mu \mathrm{m}$ wide middle section due to wider seed layer. Therefore, the model was extended with an additional 4 th part describing this middle section (see Figure 4 ). This shifts the area fractions to $\mathrm{I}=16.7 \%$, II $=20.5 \%$, III $=19.9 \%$, and IV $=42.9 \%$.

Area IV is assumed to be a lambertian emitter, that is, in each angle the same amount of light is reflected. The waviness in the micrometer range and also the rough microstructure of the plated silver make the assumption reasonable (see Figure 5).

Light that is reflected from the metal, with an angle $>$ $40.9^{\circ}$, hits the glass-air interface $100 \%$ and is reflected back to the silicon. In order to calculate the part of the reflected light at smaller angles, the light is divided into two halves: one is $s$-polarised and the other half is $p$-polarised [8]. For the varying angle of incidence $\varphi$ Snell's law of refraction is applied

$$
R_{\mathrm{ref}}=\left(\frac{\eta_{0}-\eta_{1}}{\eta_{0}+\eta_{1}}\right)^{2}
$$

with $\eta_{0,1}=\mathbf{H} / \mathbf{E}$ the optical admittance and the index 0 for air and 1 for glass. Figure 6 shows that for small angles

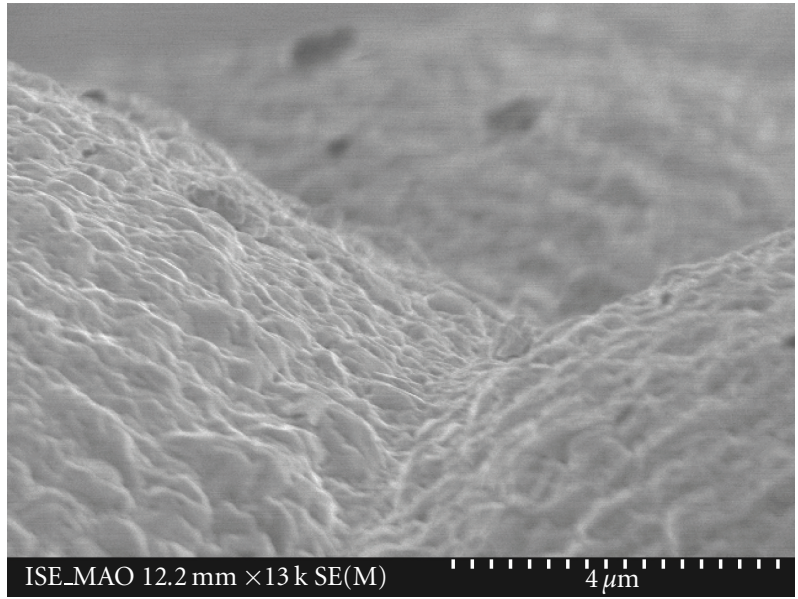

Figure 5: Microstructure of the plated silver surface.

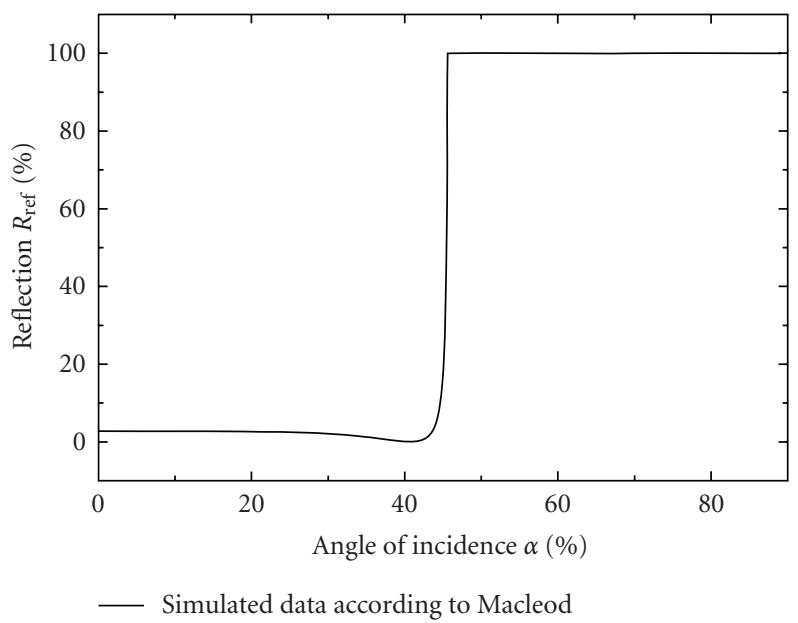

Figure 6: Simulated data for the reflection at the interface glass-air.

the reflection is smaller than $5 \%$ and just before $\alpha=40.9^{\circ}$ increases rapidly.

The effective width EW illustrates the fraction of the absorption and the loss of reflection of a finger and is 100\% minus the light that reaches the silicon. The amount of light that reaches the silicon is $100 \%$ minus the losses of area III $\left(L_{\mathrm{III}}\right)$ and IV $\left(L_{\mathrm{IV}}\right)$ multiplied by the reflection of the silver

$$
\mathrm{EW}=100 \%-\left(100 \%-L_{\mathrm{III}}-L_{\mathrm{IV}}\right) \cdot R_{\mathrm{Ag}} .
$$

The fraction of the angle of the light being reflected out of the module is

$$
d \alpha=\frac{1}{2 \pi} \int_{0}^{2 \pi} d \varphi \int_{0}^{\alpha} d \vartheta \sin \vartheta=[-\cos \vartheta]_{0}^{\alpha}=0.245
$$

with $\varphi, \vartheta$ the spherical coordinates.

With the data of Figure 6 , that about $96 \%$ of the light with an angle $<\alpha$ leaves the module and that $42.9 \%$ of the covered area of the finger is IV, it results

$$
L_{\mathrm{IV}}=0.245 \cdot 0.429 \cdot 96 \% \text {. }
$$


TABLE 1: Calculated and measured effective widths for the three different methods for the aerosol and screen-printed cells. The screen-printed column includes the mean value for the screenprinted and the one with a plated step.

\begin{tabular}{lcc}
\hline Method & Aerosol-printing & Screen-printing \\
\hline Theoretical value & 34.5 & - \\
Global measurement & 36.0 & 41.9 \\
LBIC measurement & 42.8 & 52.3 \\
\hline
\end{tabular}

Because of the rough microstructure, not all of the light of area III leaves the module directly. Half of it is assumed to behave like a lambertian surface so that

$$
L_{\text {III }}=0.623 \cdot 0.199 \cdot 96 \% \text {. }
$$

In this model, multiple reflections between finger and the interface are neglected as well as the absorption within the glass layer. The measurement for the reflection of the plated silver between $600 \mathrm{~nm}$ and $1000 \mathrm{~nm}$ is shown in Section 3 and is $R_{\mathrm{Ag}}=83.7 \%$.

The effective width EW of an aerosol-printed and plated finger with an encapsulated glass layer above then results in $\mathrm{EW}=34.7 \%$ (of the geometrical width).

\section{Cell Preparation}

For the experiment, four $p$-type Cz-silicon textured wafers with industrial emitter $(60 \mathrm{Ohm} / \mathrm{sq})$ and Al-BSF were processed with different fingers (see Table 2). Two cells received a $50 \mu \mathrm{m}$ wide seed layer with the aerosol printer. Afterwards, the fingers were thickened of about $20 \mu \mathrm{m}$ by LIP. These two cells differed in their finger spacing: one cell had a line spacing of $1.955 \mathrm{~mm}$ (Awd); the small spacing was half of it (Asd). The two screen-printed cells are identical, though one was plated additionally, which is the reason why the geometrical width is greater. The finger widths are based on microscope measurements. After LIP, the cells were encapsulated into a module using EVA.

\section{Global Measurement}

At this measurement, as proposed by Stuckings and Blakers [7], a $0.5 \mathrm{~cm}$ wide and $1 \mathrm{~cm}$ high area is illuminated with a wavelength dependent spectrum between $600 \mathrm{~nm}$ and $1000 \mathrm{~nm}$ and the reflection is measured. The encapsulated cells have been measured including 5 horizontal adjusted fingers in the measurement area. For the sample Asd, 10 fingers were included. In Figure 7, the wavelength-dependent reflection $R_{\text {ref }}$ for the four cell types is plotted. Additionally, the following samples were studied: one sample without metal, one completely covered with screen-printed silver, and one completely of plated silver. As expected, the reflection increases with the covered metal fraction. Comparing the completely covered samples, it can be concluded that the plated silver reflects more light than the screen-printed silver.

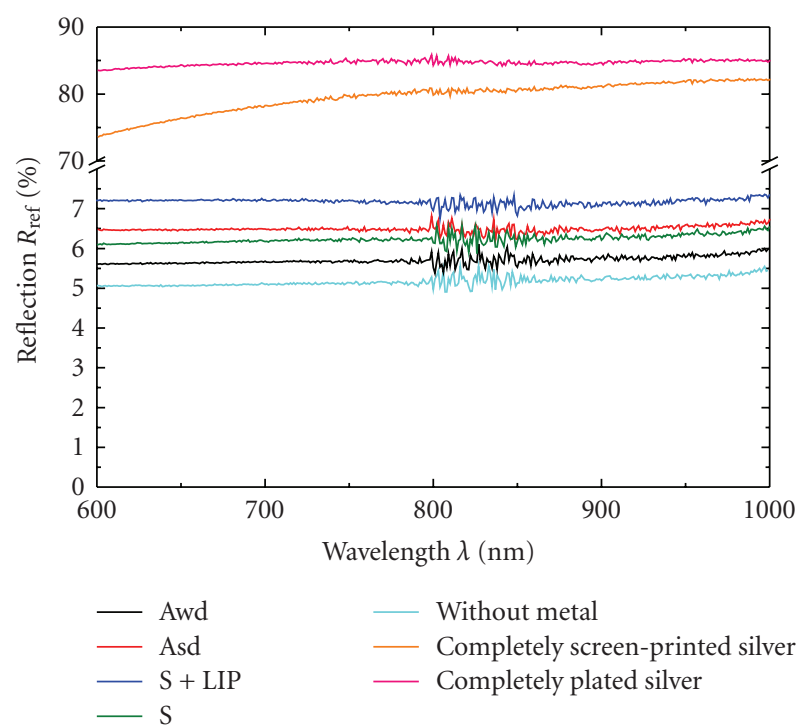

Figure 7: Reflection curves of the global measurement of the four processed cells of Table 2 and additionally one cell without metal, one completely covered with screen-printed silver and one with completely plated silver.

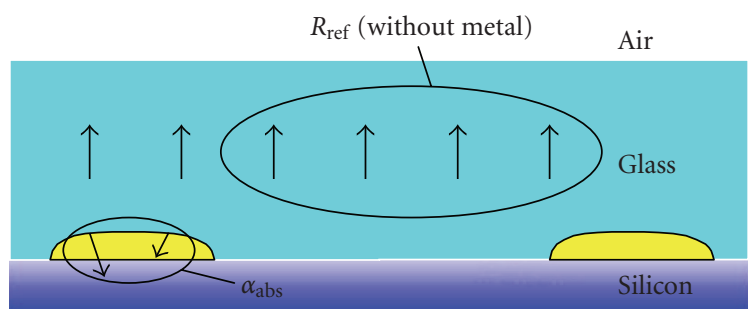

Figure 8: Drawing for clarifying the optical loss OL: the reflection signal of the sample without metal is subtracted and the absorption of the silver is added to the reflection signal of each of the four cells.

The optical loss (OL) of a metal finger can be calculated by using the following equation, according to the method of Stuckings and Blakers [7]:

$$
\left.\mathrm{OL}=R_{\text {ref }}(\text { cell })-R_{\text {ref }} \text { (without metal }\right) A_{\text {ref }}+\alpha_{\text {abs }} A_{\text {abs }} .
$$

Optical loss is the reflection of a cell minus the reflection without metal plus the absorption of the silver finger $\alpha_{\mathrm{abs}}$. $\alpha_{\text {abs }}$ equals $100 \%-R_{\text {ref }}$ (completely screen-printed silver), respectively, $R_{\text {ref }}$ (completely plated silver). The reflections are weighted with the covered areas $A_{\text {ref }}$ and $A_{\text {abs }}$, which are determined from the microscope pictures. Schematically, the calculation is clarified in Figure 8.

The data for the optical loss are plotted in Figure 9, showing how much light is lost by each type of area.

Regarding the fraction of the optical loss to the reflection of a flat finger that reflects all the light or differently expressed the fraction of OL to the fraction of the finger coverage $p \mathrm{GW}$, we receive the effective width

$$
\mathrm{EW}=\frac{\mathrm{OL}}{p \mathrm{GW}} .
$$


TABLE 2: Explanation of the four different cells that have been processed.

\begin{tabular}{lccc}
\hline Abbreviation & Explanation & Geometrical finger width GW $[\mu \mathrm{m}]$ & $\begin{array}{c}\text { Fraction of finger coverage of } \\
\text { the global measurement area } \\
p \mathrm{GW}[\%]\end{array}$ \\
\hline Awd & Aerosol-printed cell with wide line distance & $65 \pm 4.9$ & 3.25 \\
Asd & Aerosol-printed cell with small line distance & $70.6 \pm 4.4$ & 7.06 \\
S & Screen-printed cell & $124.8 \pm 4.3$ & 6.24 \\
S + LIP & Screen-printed cell + LIP & $135.8 \pm 3.9$ & 6.79 \\
\hline
\end{tabular}

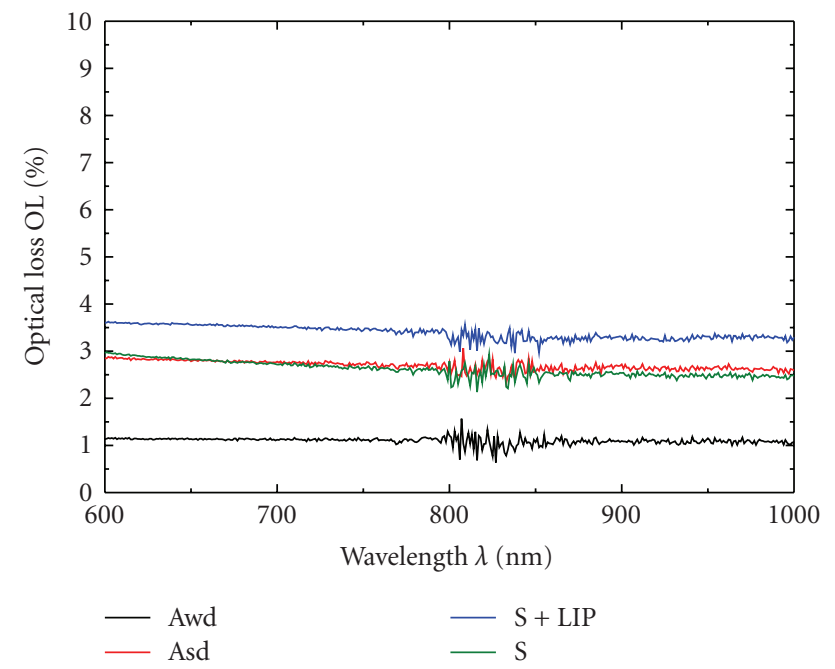

FIGURE 9: Curves for the optical loss OL for the four different cell types that are calculated according to (8).

This is shown in Figure 10. The effective widths of all fingers are clearly under $60 \%$, which means that just up to $60 \%$ of the finger area are effectively shading the cell and at least $40 \%$ of the light striking the finger are still producing current (see Figure 3). Furthermore, the effective widths for the aerosolprinted cells are much smaller than for the screen-printed fingers. Averaging the data, the aerosol-printed and plated cells have an effective width of $36 \%$, the screen-printed finger $42 \%$, and the additionally plated screen-printed finger an EW of $50 \%$.

\section{LBIC Measurement}

Usually, the LBIC method is used to measure the spatially resolved IQE by scanning a cell with a laser beam [9]. In this experiment, the laser beam with a wavelength of $833 \mathrm{~nm}$ and a diameter of $6 \mu \mathrm{m}$ was scanning a finger (of the four different cells above) 10 times with a displacement of $3.1 \mu \mathrm{m}$, while measuring the reflection. The data of two fingers are shown in Figures 11 and 12. Comparing them, the screen-printed finger looks wider than the aerosol-printed finger and has a higher maximal reflection. But since the geometrical widths are different their optical behaviour is uncertain.

In order to compare the data with the measurement setup above, the following procedure was applied. The 10 scans

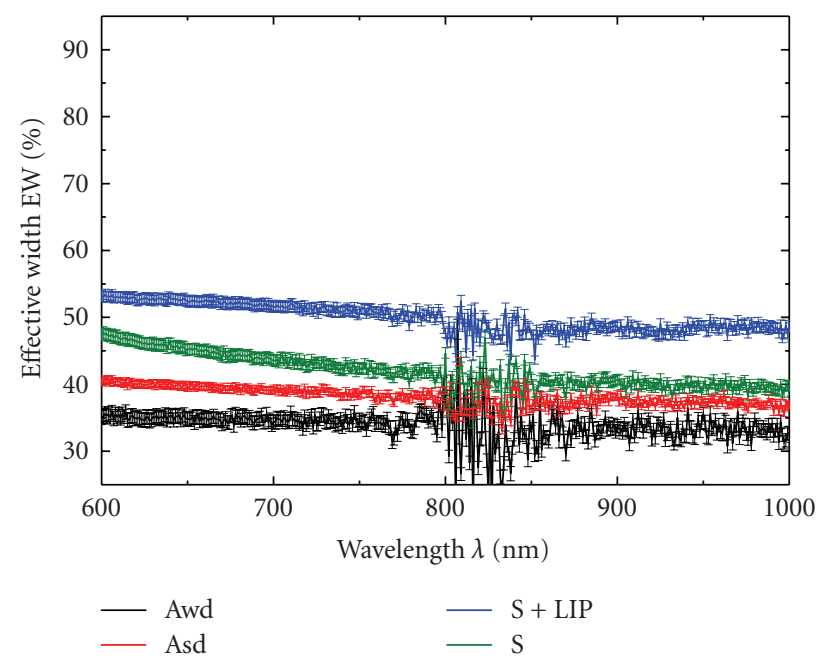

Figure 10: Effective width EW for the four different cells (see Table 2) with an error of the finger width of $4 \mu \mathrm{m}$ and a measurement signal of $2 \%$.

were averaged and the signal was integrated and divided by GW. The loss by reflection is shown in Figure 13. Beside the loss by reflection, the loss by absorption of the silver has to be included because not $100 \%$ - loss of reflection is the amount of light that reaches the silicon. The amount is only $\alpha_{\text {in }}=(100 \%-$ loss of reflection $) \cdot R_{\mathrm{Ag}}$. So the effective width is $\mathrm{EW}=100 \%-\alpha_{\mathrm{in}}$, which is plotted in Figure 13 .

The trend observed for this data is the same as for the global method. The aerosol-printed cells are optically narrower than the screen-printed cells. The aerosol-printed cells have an EW of 43\% (average of Awd and Asd) and the screen-printed as well as the one with LIP has an EW of 52\%.

\section{Conclusion}

The effective reflection of different types of metal fingers, produced by industrial feasible technologies, has been analysed by theory and experiment. The theory showed that the effective shading area is significantly smaller than the geometrical one for a metallised front side finger. The calculated theoretical value for the aerosol-printed finger is in good agreement with the measurements (see Table 1). The small deviation probably occurs because of the assumption of the lambertian emitter of the surface. Both measurement techniques (the global and the locally resolved one) showed 


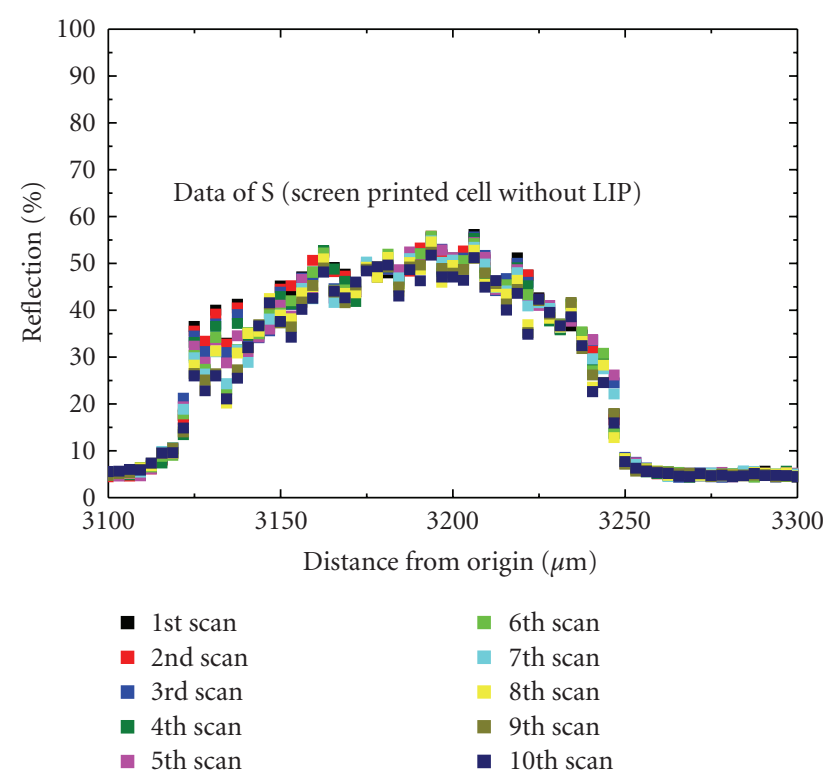

FIGURE 11: Locally resolved reflection signal using an LBIC setup of a screen-printed nonplated finger.

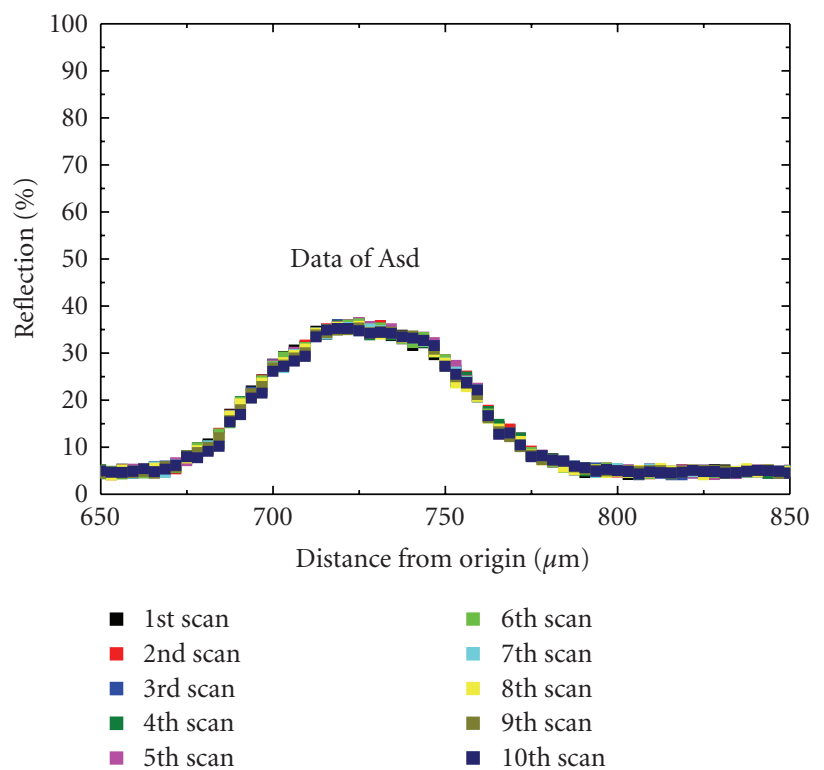

FIGURE 12: Locally resolved reflection signal using a LBIC setup of an aerosol-printed and plated finger.

that the effective width EW for a finger is between a third and about half of the geometrical width. In both cases, the aerosol-printed plus plated finger has not only a smaller geometrical finger width than the screen-printed ones but also a smaller effective (optical) finger width. Averaging the values for the aerosol-printed cells the effective width is $38 \%$, which is slightly higher than the values Blakers $[5,6](36 \%)$ and Stuckings and Blakers [7] (30-35\%) received for contacts with a very narrow seed layer and electroplating. This is due to the wider flat middle part of the aerosol-printed fingers and therefore these results are in good agreement.

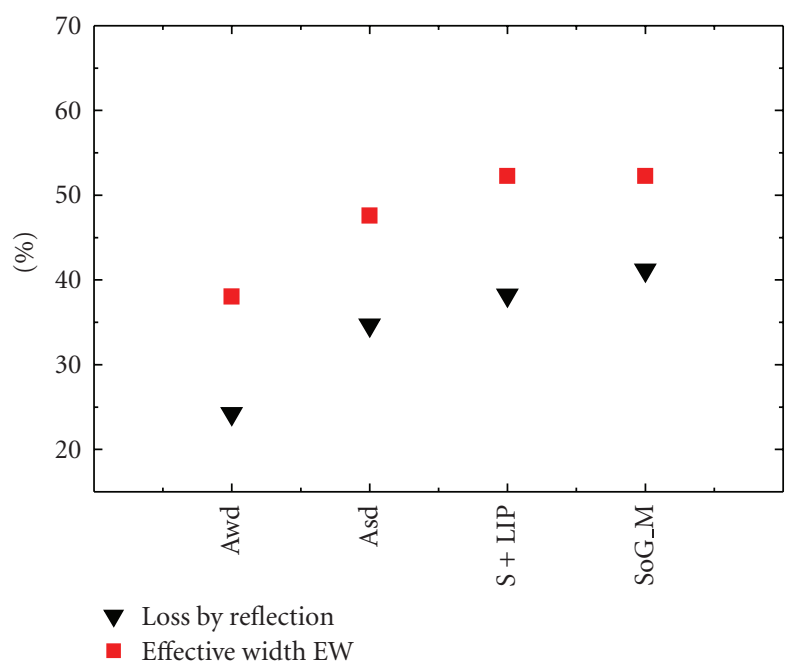

FIGURE 13: Loss by reflection and effective width EW for the LBIC measurement of the four differently processed cells.

\section{Acknowledgments}

The authors would like to thank A Filipovic, D. Schmidt, and E. Schaeffer for cell processing and M. Rinio for the LBIC measurements.

\section{References}

[1] M. Hörteis, A. Mette, P. L. Richter, F. Fidorra, and S. W. Glunz, "Further progress in metal aerosol jet printing for front side metallization of silicon solar cells," in Proceedings of the 22nd European Photovoltaic Solar Energy Conference and Exhibition, Milan, Italy, September 2007.

[2] A. Mette, P. L. Richter, M. Hörteis, and S. W. Glunz, "Metal aerosol jet printing for solar cell metallization," Progress in Photovoltaics: Research and Applications, vol. 15, no. 7, pp. 621627, 2007.

[3] S. W. Glunz, J. Knobloch, D. Biro, and W. Wettling, "Optimized high-efficiency silicon solar cells with $\mathrm{J}_{\mathrm{sc}}=42 \mathrm{~mA} / \mathrm{cm}^{2}$ and $\eta=$ 23.3\%," in Proceedings of the 14th European Photovoltaic Solar Energy Conference (EUPVSEC '97), pp. 392-395, H.S. Stephens \& Associates, Barcelona, Spain, June-July 1997.

[4] A. Mette, C. Schetter, D. Wissen, S. Lust, S. W. Glunz, and G. Willeke, "Increasing the efficiency of screen-printed silicon solar cells by light-induced silver plating," in Proceedings of the 4th IEEE World Conference on Photovoltaic Energy Conversion (WCPEC '06), vol. 1, pp. 1056-1059, Waikoloa, Hawaii, USA, May 2006.

[5] A. W. Blakers, "Shading losses of solar-cell metal grids," Journal of Applied Physics, vol. 71, no. 10, pp. 5237-5241, 1992.

[6] A. W. Blakers, "Low loss metallisation of solar cells," in Proceedings of the 23rd IEEE Photovoltaic Specialists Conference (PVSC '93), pp. 347-351, Louisville, Ky, USA, May 1993.

[7] M. F. Stuckings and A. W. Blakers, "A study of shading and resistive loss from the fingers of encapsulated solar cells," Solar Energy Materials Solar Cells, vol. 59, no. 3, pp. 233-242, 1999.

[8] H. A. Macleod, Thin Film Optical Filters, Adam Hilger, Bristol, UK, 1986. 
[9] M. Rinio, H. J. Möller, and M. Werner, "LBIC investigations of the lifetime degradation by extended defects in multicrystalline solar silicon," in Proceedings of the 5th International Workshop on Beam Injection Assessment of Defects in Semiconductors (BIADS '98), Solid State Phenomena Series, Scitec Publications, Schloss Wulkow, Germany, August-September 1998. 

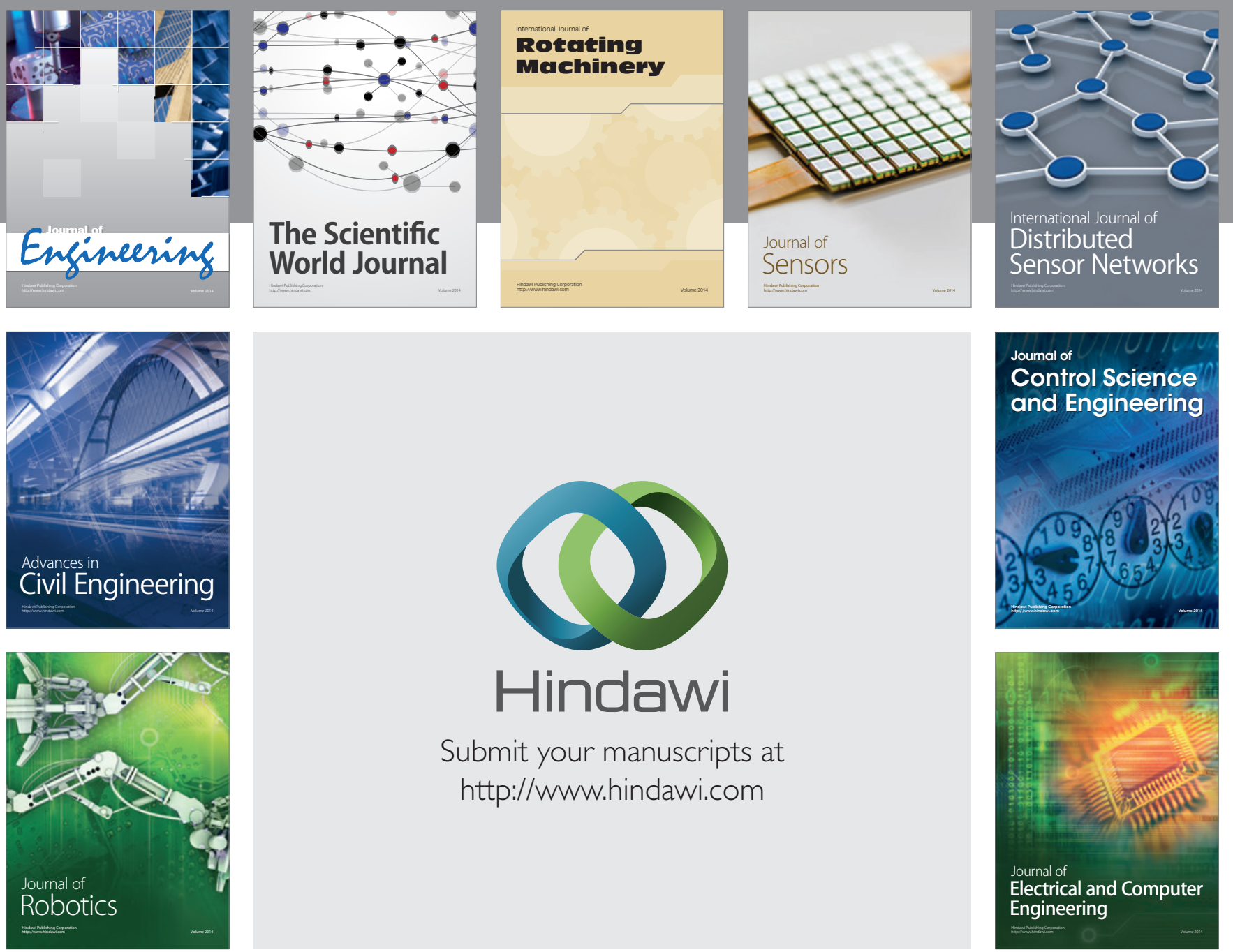

Submit your manuscripts at

http://www.hindawi.com
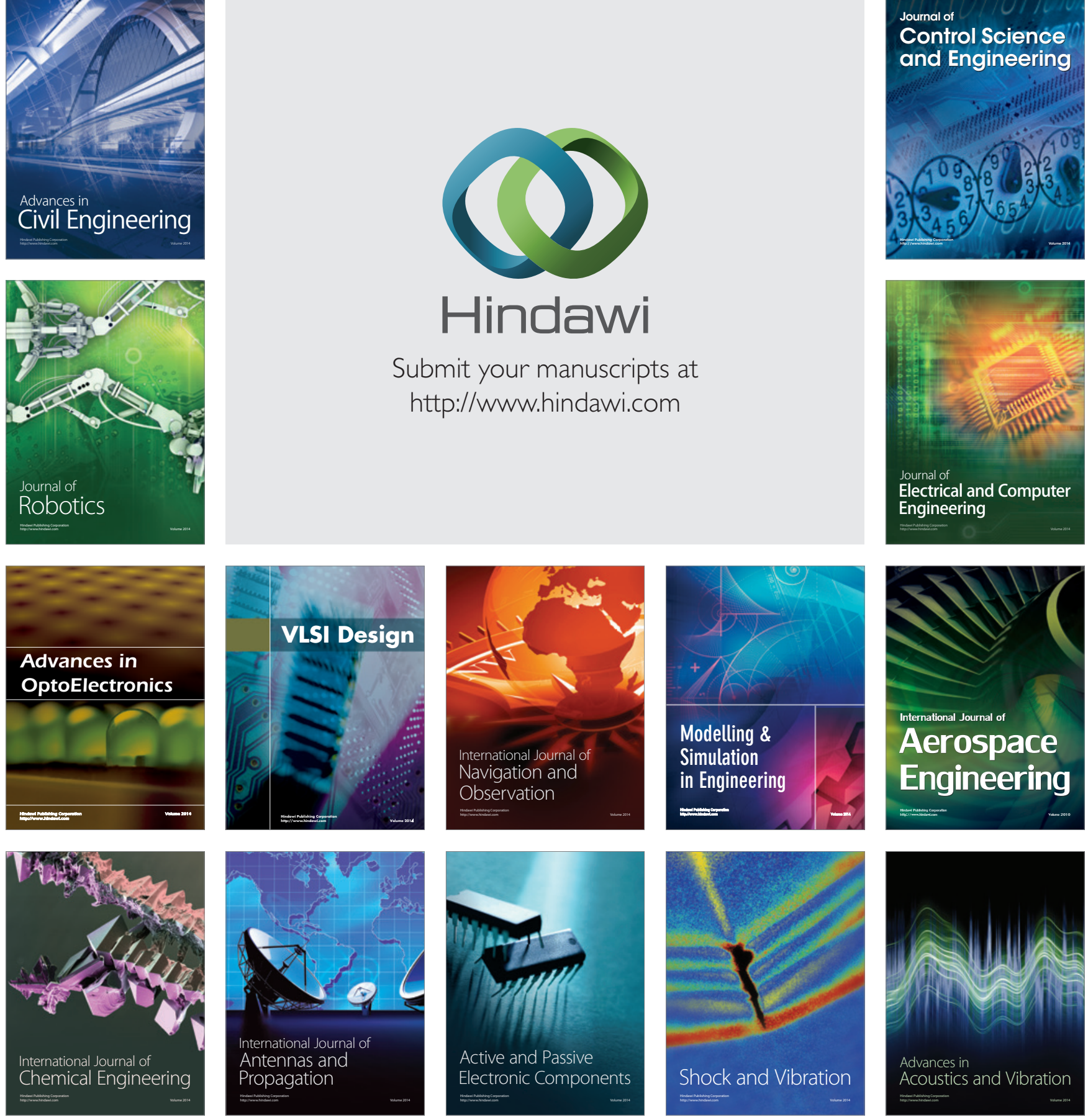